\title{
DESENVOLVIMENTO DE PRODUTOS EM SUBSIDIÁRIAS DE EMPRESAS MULTINACIONAIS NO BRASIL
}

\section{RESUMO}

O artigo tem o objetivo de responder à seguinte questão: por que subsidiárias de empresas multinacionais estrangeiras realizam projetos de desenvolvimento de produto (DP) para mercados externos? Para isso, foi realizada uma análise de conglomerados e testes não paramétricos de hipóteses usando uma amostra de mais de 140 unidades de desenvolvimento de produto localizados no Brasil. Este estudo identifica cinco papéis estratégicos significativamente distintos: os adaptadores locais, os inovadores nascentes, os inovadores locais, os inovadores para mercados emergentes e os inovadores globais. A caracterização dos conglomerados mostra que unidades com escopo de mercado primordialmente local tendem a desenvolver um número maior de novos produtos à medida que sua autonomia decisória aumenta. No entanto, unidades voltadas para mercados externos podem perder autonomia decisória. A probabilidade de que uma unidade localizada em um país de médio ou baixo custo desenvolva produtos para mercados externos aumenta conforme a empresa multinacional fomenta a competição entre as subsidiárias.

\section{Dirk Michael Boehe \\ Universidade de Fortaleza}

\begin{abstract}
Why do subsidiaries of foreign owned multinational companies (MNCs) carry out product development projects for clients located abroad? In order to answer this question, we carried out a web survey with more than 140 valid responses and used cluster analysis and non parametric hypothesis tests. This study identifies five significantly distinct strategic roles, local adaptors, nascent innovators, local innovators, innovators for emerging markets and global innovators. Based on the profiles of these roles, we conclude that subsidiaries with local market scope tend to develop more new products when they have higher decision-making autonomy. Subsidiaries which develop new products for external markets, however, might see their decision-making autonomy reduced. Our results also suggest that subsidiaries are more likely to develop new products for external markets multinationals when multinationals stimulate competition among their subsidiaries.
\end{abstract}

PALAVRAS-CHAVE Desenvolvimento de produtos, empresas multinacionais, papéis estratégicos, autonomia, mercados internos. KEYWORDS Product development, multinational enterprises, strategic roles, autonomy, internal markets. 


\section{INTRODUÇÃO}

De acordo com o World Investment Report (United Nations, 2005), a globalização das atividades de pesquisa e desenvolvimento (P\&D) realizadas por empresas multinacionais (EMN) está atingindo cada vez mais os países em desenvolvimento. Dentre os países em desenvolvimento, o Brasil é, atualmente, a quinta localização mais importante em termos de investimentos realizados por empresas em P\&D, atrás da Coréia do Sul, da China, de Taiwan e da Rússia. Além disso, é notório que quase $50 \%$ das atividades de $P \& D$ do setor empresarial no Brasil correspondem à participação de subsidiárias estrangeiras, daí a relevância do tema. Assim, busca-se, neste artigo, ir além da descrição do fenômeno, juntamente com a contribuição de explicações enraizadas na literatura recente sobre o tema. Nesse contexto, os papéis que as subsidiárias estrangeiras localizadas em um país em desenvolvimento desempenham nas estratégias de inovação das multinacionais é um tema novo, pois esse assunto foi abordado até hoje apenas pela literatura originada em países industrializados.

Os papéis estratégicos de subsidiárias de EMNs têm sido objeto de estudos empíricos e teóricos os quais abordam, dentre outros aspectos, os determinantes de papéis específicos, tais como mandatos mundiais ou centros de excelência, a evolução de papéis estratégicos e as relações entre subsidiárias e outras unidades da corporação (Gupta e Govindarajan, 1991; Roth e Morrison, 1992; Andersson, Forsgren, 2000; Feinberg, 2000; Holm e Pedersen, 2000; Frost, Birkinshaw, Ensign, 2002).

Nesse campo de pesquisas, o presente artigo enfoca papéis estratégicos na área de desenvolvimento de produtos e responde, dessa forma, a uma exigência apresentada em vários estudos, a saber, focar as pesquisas sobre papéis estratégicos e os seus atributos em áreas funcionais específicas da organização, tais como produção, logística, marketing ou pesquisa e desenvolvimento (Birkinshaw e Morrison, 1995; Young e Tavares, 2004).

Com a predominância de produtos e plataformas globais em grande parte das indústrias, a capacidade de desenvolver novos produtos destinados a mercados externos torna-se cada vez mais importante. Mais do que isso, as subsidiárias que desenvolvem novos produtos para mercados globais são, provavelmente, mais resistentes às crises econômicas, tanto no mercado interno quanto no mercado internacional, pois podem compensar mais facilmente eventuais oscilações na demanda em qualquer um desses mercados. Por essas razões, enfocam-se neste artigo as atividades de desenvolvimento de novos produtos para mercados externos.
A principal questão de pesquisa é compreender por que as subsidiárias realizam projetos de desenvolvimento de produto (DP) para mercados externos. As pesquisas realizadas no Brasil têm evidenciado a relevância desse tema e deram diferentes respostas para essa questão, tais como: os custos de DP, principalmente os custos da mão-de-obra; as vantagens competitivas em função da desvalorização cambial após o ano de 1998; os incentivos de políticas governamentais, principalmente os da Lei da Informática; a maior autonomia da equipe local de DP em função desses incentivos; o reconhecimento de competências específicas pela matriz; as características específicas do mercado local; as formas de coordenação das atividades globais de $\mathrm{P} \& \mathrm{D}$, tais como a centralização ou a descentralização; a redução de barreiras comerciais e a tendência aos produtos globais; o aproveitamento do Brasil como plataforma de exportação e de DP voltada para mercados de países em desenvolvimento, devido à competência local de desenvolver soluções mais econômicas; as iniciativas e o empreendedorismo de executivos das subsidiárias brasileiras (Camargos, 2000; Galina, 2003; Consoni, 2004; Boehe e Zawislak, 2004; Oliveira Junior e Borini, 2005).

Os estudos mencionados não problematizam suficientemente diferentes formas de coordenação das atividades de desenvolvimento de produto entre as unidades da multinacional, formas essas que podem proporcionar explicações decisivas para os papéis das subsidiárias nas estratégias de inovação das EMNs. Por exemplo, algumas pesquisas sugerem que a autonomia decisória da subsidiária frente à sua matriz não constitui uma condição suficiente para a determinação do papel da subsidiária (Roth e Morrison, 1990; Asakawa, 2001; Frost, Birkinshaw e Ensign, 2002). Diante da grande quantidade de contribuições que usam o conceito da autonomia, é surpreendente que outras formas de coordenação não tenham recebido muita atenção. Se a autonomia, ou seu inverso, o controle decisório (O'Donnell, 2000), remete à lógica da subordinação na hierarquia organizacional, cabe questionar por que conceitos que remetem a formas de coordenação semelhantes a um mercado interno não receberam a mesma atenção. Um estudo pioneiro de múltiplos casos, mas ainda solitário nessa área (Birkinshaw e Fey, 2000), define o conceito de mercado interno e outras formas de coordenação que estimulam a competição entre as subsidiárias em organizações globais de pesquisa e desenvolvimento, mas não discute explicitamente a eventual existência de uma relação entre esse conceito e papéis estratégicos. Além disso, Birkinshaw e Fey (2000) recomendam para futuros estudos que a relevância do conceito seja testada por meio de pesquisas de grande escala (surveys). 
O propósito do presente artigo é preencher essa lacuna de explicação, levando em conta ambos os conceitos, a autonomia e a competição interna entre as subsidiárias. Argumenta-se que a competição interna é mais relevante para explicar papéis estratégicos em desenvolvimento de produto do que a autonomia, especialmente quando a subsidiária está localizada em um país competitivo em custos. Nas demais seções deste artigo apresentam-se a base teórica, o método e a análise de dados, assim como a discussão e as conclusões.

\section{BASE CONCEITUAL}

Nesta seção se apresenta o estado atual de pesquisa sobre os conceitos de autonomia e competição interna, assim como suas relações com os papéis estratégicos da unidade de desenvolvimento de produto. A unidade de desenvolvimento de produto pode ser um centro de pesquisa e desenvolvimento, centro de projetos ou um departamento de engenharia de produto.

\section{Papéis estratégicos}

Neste estudo, o termo papel estratégico diz respeito à função da unidade de desenvolvimento de produto (UDP) de uma subsidiária dentro das atividades globais de $\mathrm{P} \& \mathrm{D}$ da multinacional. Raras vezes existem papéis estratégicos aplicáveis para uma subsidiária inteira, mas diferentes áreas funcionais e linhas de produtos da mesma subsidiária podem estar associadas com distintos papéis estratégicos (Rugman e Verbeke, 2001). Nesse sentido, este estudo segue a recomendação de Birkinshaw e Morrison (1995, p. 750) ao afirmarem que futuras "pesquisas precisam focalizar [unidades de pesquisa] abaixo do nível da subsidiária, de preferência em uma única função de agregação de valor, tal como a operação manufatureira ou um grupo de produto".

$\mathrm{Na}$ área de desenvolvimento de produto (DP) ainda não são conhecidos critérios para a classificação de papéis estratégicos, principalmente quando os objetos de estudo são as subsidiárias de empresas multinacionais localizadas em países emergentes. Entretanto, a literatura oferece pontos de referência a partir dos quais é possível desenvolver critérios para medir esses papéis. Para estudos sobre inovação em países de industrialização recente, a abordagem das capacidades tecnológicas parece a mais adequada, pois permite levar em conta atividades de menor sofisticação tecnológica que escapariam da atenção do pesquisador quando outras classificações fossem usadas.
Lall (1992, p. 166) aponta que "é evidente que a inovação pode ser definida de forma muito mais ampla para cobrir todos os tipos de busca e aperfeiçoamento". A partir desse ponto de vista, esse autor desenvolveu uma tipologia de capacidades tecnológicas de três níveis, abrangendo a capacidade básica, a capacidade intermediária e a capacidade avançada, e aplicou-a a diferentes áreas funcionais como as "atividades de desenvolvimento de produto".

Essa abordagem sugere que as capacidades tecnológicas podem evoluir de um baixo grau de complexidade, como atividades de rotina e menores adaptações, para um grau de alta complexidade e maior risco, como inovação de produto baseada em pesquisas científicas. A tipologia de Lall foi sucessivamente ampliada para até sete níveis de capacidades tecnológicas (Figueiredo, 2003), mas, por questões de operacionalização, o presente estudo se limita aos três níveis genéricos, de acordo com Lall (1992).

Aplicando essas categorias às áreas de desenvolvimento de produto em subsidiárias de multinacionais, é possível trabalhar com três tipos de projetos essencialmente distintos: (a) a subsidiária que adapta ("tropicaliza") produtos, desenvolvidos em outras unidades da multinacional, para as necessidades específicas do mercado em que atua; (b) a subsidiária que melhora significativamente produtos existentes; (c) e a subsidiária que cria produtos novos.

Outra dimensão importante a ser levada em consideração é a do escopo geográfico, isto é, a dos mercados atendidos pela subsidiária da empresa. Para tanto, é preciso superar a visão "clássica" da multinacional, segundo a qual o mercado da subsidiária se limita ao mercado do seu país hospedeiro, pois tal visão ignora que uma subsidiária possa evoluir (Birkinshaw e Hood, 1998) e, aos poucos, assumir responsabilidades que ultrapassem as fronteiras do mercado do país hospedeiro. Tal fato já foi comprovado por diversos estudos, dentre os quais se destacam os de Gupta e Govindarajan (1991, 1994) ou Nobel e Birkinshaw (1998), que identificaram subsidiárias com papéis estratégicos voltados para mercados globais, como o inovador global, a unidade integrada ou o adaptador internacional.

Enquanto os papéis mencionados só distinguem subsidiárias com escopo global daquelas com escopo local, Schütte (1998) introduz a categoria matriz regional, isto é, a subsidiária cuja função é produzir, servir, vender e desenvolver para os mercados da região em que está inserida. A subsidiária pode ainda ir além desses mercados regionais, adaptando, melhorando ou desenvolvendo produtos para outros mercados cujas características (nível de preços, exigências dos clientes, fatores climáticos, etc.) sejam semelhantes, por exemplo, os mercados de outros países emergentes. Essa ampliação justifica-se também 
pelas informações levantadas em entrevistas exploratórias dos autores e em estudos de outros autores. Consoni (2003), por exemplo, relata que algumas montadoras de automóveis, como a VW e a GM, possuem mandatos para os mercados de países em desenvolvimento na América Latina, no Oriente Médio e na África.

Assim, tem-se três categorias de mercados para as quais a subsidiária pode desenvolver produtos: o mercado do país hospedeiro; os mercados de outros países emergentes, tais como América Latina, África, países árabes e asiáticos, o leste europeu; e os mercados de países industrializados, como Europa, Japão, Estados Unidos e Canadá. A seguir se abordam dois conceitos que podem explicar o papel estratégico de uma subsidiária.

\section{Autonomia}

O conceito da autonomia reflete a existência ou não da hierarquia organizacional na relação entre uma subsidiária e sua matriz. Em seu texto sobre a burocracia, Weber (1963) ressalta algumas características da hierarquia organizacional, tais como as definições formais, racionais e objetivas das regras referentes aos processos e à interação das diferentes unidades da organização. O controle hierárquico das unidades subordinadas pelas unidades superiores, a estrita obediência e as sanções em caso de violação das regras são elementos essenciais desse modelo. Sopõe-se, então, que existam a distribuição de poder de acordo com os níveis hierárquicos, a imposição de normas e o controle dos meios e canais de comunicação.

Na visão da organização hierárquica da multinacional, parte-se da premissa de que as decisões na área de DP originam-se na matriz e são tomadas de forma racional do ponto de vista da empresa como um todo. Em decorrência disso, a atribuição de papéis estratégicos às UDPs é decretada de forma unilateral pela matriz, e, mais do que isso, as atividades inovadoras de maior valor agregado são mantidas na matriz, enquanto as subsidiárias realizam apenas atividades inovadoras subordinadas ao domínio tecnológico daquela. Evidentemente, isso nem sempre corresponde à realidade, pois muitas EMNs são organizações diferenciadas e complexas, nas quais podem existir diferentes grupos de interesse que competem pela influência e pelo poder na mesma empresa (Cyert e March, 1963; Ghoshal e Bartlett, 1990). Essa realidade é considerada na concepção exposta a seguir.

O conceito da autonomia é talvez o mais discutido na área de pesquisa que foca a evolução e os papéis estratégicos das subsidiárias (Ghoshal e Bartlett, 1988; Birkinshaw e Morrison, 1995; Taggart, 1997), visto que já foram publicadas várias revisões de literatura que dão especial atenção a esse conceito (Paterson e Brock, 2002; Young e Tavares, 2004).

Para Young e Tavares (2004, p. 228), a "autonomia diz respeito à liberdade restrita ou à independência disponível ou adquirida pela subsidiária que lhe permite tomar certas decisões em função de seu próprio interesse". Essa liberdade é restrita dado que é a matriz que decide sobre o grau de autonomia da subsidiária em cada área de decisão. Podem resultar disso dois cenários: se a decisão da matriz sofrer influência da subsidiária, ter-se-á a autonomia conquistada; caso contrário, a autonomia será concedida pela matriz. Ainda de acordo com esses autores, a autonomia deve estar associada a recursos gerenciais, tecnológicos ou financeiros para que as decisões da subsidiária possam ser implementadas. Ademais, a autonomia deve estar associada com motivações positivas. Assim, autonomia não deve ser confundida com decisões que possam prejudicar a corporação como um todo ou os interesses da matriz ou os de outras subsidiárias. Finalmente, autonomia também não é equivalente a descentralização, a qual "se refere ao grau de autoridade para a tomada de decisão (pela subsidiária) conforme permitido pela matriz, onde ações autônomas são possíveis" (Young e Tavares, 2004, p. 228).

Enquanto a autonomia parece ser especialmente importante do ponto de vista das subsidiárias que buscam capacitar-se tecnologicamente, a eficiência das operações da multinacional tende a ser o principal interesse da matriz (veja a próxima subseção).

Outras pesquisas mostraram que diferentes graus de autonomia podem estar associados a diferentes papéis estratégicos em subsidiárias; por exemplo, foram identificadas subsidiárias quase autônomas e altamente responsivas ao seu mercado local (Taggart, 1997). Entretanto, subsidiárias cujas atividades são voltadas para mercados externos podem ter ou baixa ou alta autonomia dependendo do grau de integração em projetos globais coordenados pela matriz. Quando essa integração é alta, como no caso dos centros de excelência, então a autonomia é geralmente baixa, mas quando a subsidiária controla atividades de produção, $\mathrm{P} \& \mathrm{D}$, logística e marketing para determinados mercados, como no caso dos mandatos mundiais, então a autonomia para DP tende a ser alta (Feinberg, 2000).

Ora, Young e Tavares (2004, p. 231) concluem que "há ainda a necessidade de distinguir as subsidiárias e seus papéis estratégicos de acordo com a significância da variável autonomia" e perguntam "quais os níveis de autonomia associados aos diferentes papéis de subsidiárias". Além disso, eles enfatizam que a variável autonomia teria que ser analisada com respeito às atividades funcionais, já que 
a autonomia pode variar ao longo da cadeia de valor. Além disso, pode-se acrescentar que a relação entre autonomia e papéis estratégicos na área de desenvolvimento de produto até hoje não foi tratada analiticamente, menos ainda em subsidiárias localizadas em países emergentes.

A partir do exposto, propõe-se a seguinte hipótese (H1): Os diferentes grupos de UDPs não se distinguem significativamente em relação à autonomia.

\section{Competição interna}

Diferentemente do conceito da autonomia e da hierarquia organizacional, Birkinshaw e Fey (2000, p. 151) reconhecem que formas competitivas de coordenação das atividades de subsidiárias receberam ainda pouca atenção na literatura acadêmica. Eles se baseiam em Hennart (1993), que argumenta, a partir do raciocínio da teoria dos custos de transação, que elementos de organização hierárquica e de mercado podem coexistir em uma empresa, sendo usado o mecanismo de preços como incentivo para que as unidades da empresa maximizem os seus desempenhos e o mecanismo de controle hierárquico para que as unidades atuem conforme as diretrizes da matriz.

Focalizando atividades de P\&D em empresas multinacionais, Birkinshaw e Fey (2000) avançam nesse campo de pesquisa e mostram no seu estudo de múltiplos casos que o conceito do mercado interno e outras formas de competição entre subsidiárias são relevantes. Ademais, eles recomendam que o conceito seja testado com base em uma amostra maior de empresas multinacionais. $\mathrm{O}$ presente estudo busca preencher essa necessidade.

Qual o significado de competição interna? O que passará a ser chamado de competição interna é uma forma de coordenação das atividades da empresa que implica a existência de concorrência entre as unidades de desenvolvimento de produto da empresa multinacional por projetos e os recursos (orçamento, número de funcionários, equipamentos) necessários para desenvolvê-los. Nesse modo de coordenação, usa-se o incentivo à concorrência entre as unidades da empresa ou o próprio mecanismo de mercado para regular as relações existentes entre elas. Em sintonia com os critérios propostos por Birkinshaw e Fey (2000), que analisaram esse mecanismo de coordenação na área de pesquisa e desenvolvimento de empresas multinacionais, algumas das características dessa forma de organizações são as seguintes:

- a possibilidade do deslocamento de projetos de desenvolvimento de produtos de uma unidade para outra em função de diferenciais de desempenho. Essa possibilidade é atrelada à existência de duplicações de capacidades tecnológicas e equipamentos de laboratório em várias subsidiárias da EMN;

- a existência de concorrência entre as unidades da empresa por projetos e os recursos necessários para desenvolvê-los (orçamento, número de funcionários, equipamentos, dentre outros);

- a hierarquia presente no controle e na avaliação central (pela matriz) do desempenho de cada unidade, geralmente em relação ao custo, à qualidade e ao time-tomarket;

- o mercado interno, presente em sistemas de livre contratação entre as subsidiárias, sendo que algumas subsidiárias atuam como clientes que encomendam serviços tecnológicos ou projetos completos de desenvolvimento de produto de outras subsidiárias, os fornecedores;

- a competição interna na sua forma extrema pode até mesmo funcionar como um leilão no qual várias UDPs façam ofertas e a UDP que apresente a melhor oferta em termos de custo, qualidade e tempo de entrega pode levar o projeto;

- a valorização do empreendedorismo, especificamente a propensão de correr riscos aceitando projetos difíceis e sob pressão de tempo, assim como as iniciativas para "vender" as próprias capacidades e projetos a outras unidades da empresa.

No que diz respeito à relação entre o modo de coordenação da competição interna e os papéis estratégicos, não se dispõe ainda de uma convincente explicação teórica. Entretanto, pode-se supor que a competição interna abra a uma subsidiária mais oportunidades para a realização de atividades inovadoras para o exterior do que a ausência desse modo de coordenação, desde que ela tenha vantagens em custos, qualidade e time-to-market. Esse modo de coordenação constitui um incentivo para as subsidiárias realizarem projetos para mercados externos; portanto, se esse incentivo for efetivo, a inserção global das subsidiárias em DP deve aumentar. A efetividade desse incentivo depende, provavelmente, não somente do desempenho no processo de DP da unidade, mas também da competitividade internacional do país onde ela está localizada.

Logo, é importante observar a posição relativa de um país hospedeiro em termos de competitividade internacional. Por exemplo, os custos dos salários podem ter uma forte influência nesse quesito, sendo que cerca de 50\% do custo das atividades de P\&D industrial em países industrializados (como França, Alemanha, Japão, Holanda, Reino Unido e Estados Unidos) pode ser atribuído aos salários (Dougherty et al., 2002, p. 23). Nesse contexto, 
deve-se lembrar que, além desses países de alto custo, há países de médio custo, como o México e o Brasil, assim como países de baixo custo, como a Índia e a China. Cabe destacar que salários baixos somente podem levar a uma vantagem competitiva se, ao mesmo tempo, a qualidade da mão-de-obra for alta.

Além dos custos de salários, existem outros fatores que influenciam os custos de DP, tais como incentivos governamentais (por exemplo, a Lei da Informática no Brasil), a implementação ou atualização de laboratórios e equipamentos para pesquisa e desenvolvimento ou a taxa de câmbio. A competitividade internacional em atividades inovadoras parece ser um fenômeno complexo; é, portanto, difícil chegar a conclusões definitivas no tocante à influência da competição interna para os papéis estratégicos em DP.

Esse raciocínio sustenta a introdução da seguinte hipótese $\left(\mathrm{H}_{2}\right)$ : Os diferentes grupos de UDPs não se distinguem significativamente em relação à competição interna.

\section{MÉTODO}

\section{Coleta de dados}

Entre abril e julho de 2004 foram contatadas 270 unidades de desenvolvimento de produto em subsidiárias de empresas multinacionais no Brasil. Desse total, 146 responderam ao questionário enviado, o que equivale a uma taxa de resposta de 53\%. Inicialmente, o contato foi feito com os gerentes da UDP; nos casos em que estes não estavam disponíveis durante a pesquisa, solicitou-se que o questionário fosse repassado a um gerente de projeto que interagisse de forma contínua com outras subsidiárias e a matriz no exterior.

Tendo em vista que a comprovação da validade de conteúdo e do construto é fundamental para esse tipo de pesquisa, ambas foram testadas conforme se segue. A validade de conteúdo foi testada mediante a revisão do questionário por vários pesquisadores das áreas de gestão da inovação e de marketing, que fizeram sugestões referentes às formulações, às escalas e à pertinência de algumas questões, dentre outros. Já a validade do construto, foi testada em duas etapas: na primeira, realizou-se um estudo de casos exploratório, onde foram coletados dados secundários e primários, mediante visitas em 25 subsidiárias de empresas multinacionais. Na segunda etapa, diferentes versões do questionário foram encaminhadas para alguns dos entrevistados do estudo exploratório. As respostas desses questionários estruturados foram comparadas com os dados obtidos nas entrevistas diretas. Nos questionários em que foram verificadas diferenças entre as respostas, o respondente foi contatado com a finalidade de obter esclarecimentos e informações adicionais, e facilitar a identificação das razões dessas diferenças. Com base nessa análise, o questionário foi modificado e, na sequência, foram realizadas mais rodadas de testes. Além disso, aproveitou-se para conduzir testes do funcionamento técnico do questionário.

\section{Construtos e indicadores}

Enfocando exclusivamente decisões na área de DP, a presente forma de operacionalização se inspira principalmente nos trabalhos de Nobel e Birkinshaw (1998), bem como nos de Anderson e Forsgren (1996), e busca captar o controle exercido pela matriz em relação à tomada de decisão para iniciar projetos, seja de adaptação, seja de novos produtos; lançar produtos no mercado nacional e internacional; capacitar-se tecnologicamente, seja por meio da definição do orçamento para DP, seja por meio de parcerias com organizações externas.

Para mensurar o nível de autonomia, criou-se uma escala somada cujo alpha de Cronbach foi de 0,78.

Os mecanismos e os critérios para a atribuição de projetos focam principalmente avaliar a intensidade da competição entre as UDPs da multinacional. Alguns dos indicadores do constructo foram adaptados a partir do estudo de Birkinshaw e Fey (2000), mas é importante notar que o desenho de pesquisa desses autores era diferente (estudo exploratório de cinco casos em entrevistas pessoais) de uma survey auto-aplicável de grande escala. Por esse motivo, os indicadores tinham que ser modificados. Ademais, em função da notória falta de pesquisas de grande escala que levem em conta o conceito da competição interna, não se sabe se o conceito abarca dimensões distintas.

A partir de uma análise fatorial com os indicadores do construto, foram usados coeficientes de regressão com cinco itens do construto competição interna (alpha de Cronbach é de 0,72).

\section{ANÁLISE DOS DADOS}

Esta seção aborda três aspectos da análise de dados: a identificação e a transformação das variáveis a serem usadas na análise de conglomerados, a análise de conglomerados propriamente dita e a caracterização dos conglomerados com base nos dois conceitos, autonomia em desenvolvimento de produto e competição interna entre as unidades de desenvolvimento de produto da empresa multinacional. 


\section{Identificação e transformação de variáveis}

Os produtos dos indicadores referentes a projetos e mercados geram nove novos indicadores, que refletem a distribuição das atividades das UDPs. Desses nove novos indicadores, serão usados três para a análise de conglomerados, quais sejam: desenvolvimento de novos produtos para o Brasil, desenvolvimento de novos produtos para países emergentes, e desenvolvimento de novos produtos para países industrializados.

A escolha desses três indicadores se deve às premissas da análise de conglomerados: a ausência de multicolinearidade entre os indicadores, a independência e a comensurabilidade dos indicadores. Do ponto de vista conceitual, três indicadores são suficientes para esse tipo de análise, pois eles refletem melhor o foco desta pesquisa, isto é, a ocorrência de atividades inovadoras (desenvolvimento de novos produtos). Os indicadores foram transformados em escores-z para dar conta da comensurabilidade dos indicadores.

\section{Identificação e validação de conglomerados}

Nesta análise, escolheu-se o algoritmo Ward pelas seguintes razões: ele tende a homogeneizar o tamanho dos conglomerados, o que evita que observações extremas sejam separadas em conglomerados demasiadamente pequenos; os demais algoritmos (com exceção do Within group) produziram distribuições iniciais muito desequilibradas ou levaram a soluções finais com pouquíssimas observações.

Como os algoritmos disponíveis para esse tipo de análise não determinam o número de conglomerados, foi preciso estabelecer critérios baseados na teoria ou em estudos empíricos anteriores. Em estudos realizados em outros países, foram identificados de três a quatro conglomerados (Barlett e Ghoshal, 1989; Gupta e Govindarajan, 1991; Nobel e Birkinshaw, 1998). De acordo com critérios empíricos, recomenda-se que o número de conglomerados seja pequeno e o número de observações por conglomerado, grande; uma aproximação mais específica é a de Lehmann (1979, apud Roth e Morrison, 1990), que indica que o número de conglomerados deveria cair entre $\mathrm{n} / 50$ e $\mathrm{n} / 30$, ou seja, três e cinco conglomerados para o presente estudo.

Uma solução de três conglomerados suprimiria as UDPs que possuem uma forte participação com novos produtos em mercados de países industrializados. No entanto, esse conglomerado, chamado por outros pesquisadores de inovadores globais (Gupta e Govindarajan, 1991), é fundamental para a ênfase desta pesquisa e as análises subseqüentes. Por meio de uma solução com cinco conglomerados, é possível identificar um tipo reconhecido na literatura, o inovador local (Gupta e Govindarajan, 1991), o que não seria possível com a solução de quatro conglomerados. Portanto, a escolha de cinco conglomerados é justificável diante das características específicas do Brasil, dos propósitos desta pesquisa e das orientações dadas pela literatura.

A combinação das análises hierárquicas e não hierárquicas de conglomerados é recomendada para realizar ajustes finos dos conglomerados. Para a análise não hierárquica, foi usado o algoritmo k-means. Feito isso, os 15 centróides foram retransformados na escala original (em percentagens), para facilitar a interpretação (veja a Tabela 1).

De acordo com os dados apresentados na Tabela 1 , o conglomerado I contém as UDPs menos inovadoras em termos de criação de novos produtos ( $9 \%$ das atividades
Tabela 1 - Solução final de conglomerados

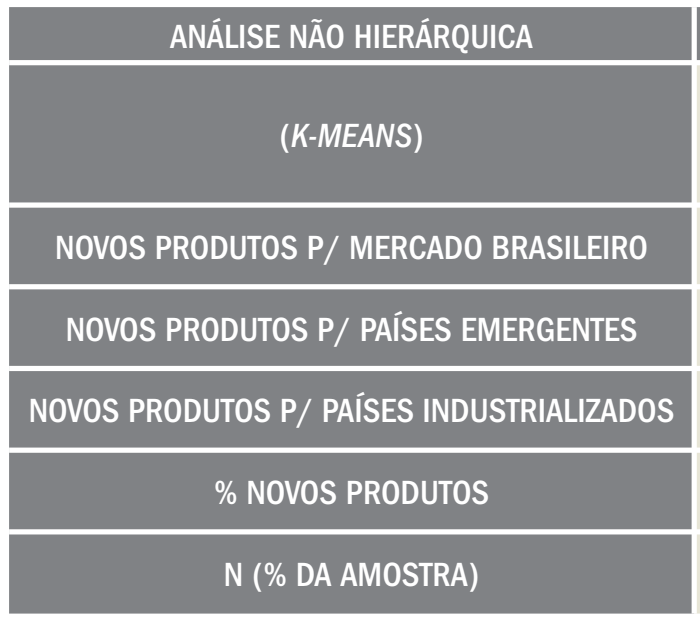

\begin{tabular}{|c|c|c|c|c|}
\hline \multicolumn{5}{|c|}{ CONGLOMERADOS } \\
\hline $\begin{array}{c}\text { Adaptador } \\
\text { local }\end{array}$ & $\begin{array}{c}\text { In Inador } \\
\text { nascente }\end{array}$ & $\begin{array}{c}\text { III } \\
\text { Inovador } \\
\text { local }\end{array}$ & $\begin{array}{c}\text { IV } \\
\text { Inovador } \\
\text { merc. em. }\end{array}$ & $\begin{array}{c}\text { V } \\
\text { Inovador } \\
\text { global }\end{array}$ \\
\hline $7 \%$ & $32 \%$ & $\mathbf{8 1} \%$ & $36 \%$ & $26 \%$ \\
\hline $1 \%$ & $8 \%$ & $2 \%$ & $35 \%$ & $3 \%$ \\
\hline $2 \%$ & $5 \%$ & $2 \%$ & $12 \%$ & $45 \%$ \\
\hline $9 \%$ & $45 \%$ & $85 \%$ & $83 \%$ & $74 \%$ \\
\hline $74(50 \%)$ & $36(25 \%)$ & $16(11 \%)$ & $9(6 \%)$ & $11(7,5 \%)$ \\
\hline
\end{tabular}


são dedicadas ao desenvolvimento de novos produtos); o conglomerado II contém as UDPs medianamente inovadoras (45\%), mas que ainda dedicam a maior parte das suas atividades à adaptação e à melhoria de produtos desenvolvidos no exterior; enquanto os conglomerados III (85\%), IV (83\%) e V (74\%) são os que mais desenvolvem novos produtos (e menos se limitam à adaptação e à melhoria de tecnologias desenvolvidas no exterior). Apesar de apresentarem participações semelhantes no desenvolvimento de novos produtos, é importante notar que estes são destinados a mercados essencialmente distintos: enquanto, no caso do conglomerado III, quase todos os novos produtos são destinadas ao mercado brasileiro, no conglomerado IV, partes iguais dos novos produtos são destinados aos mercados de países emergentes e ao mercado brasileiro. O conglomerado IV se destaca dos demais por ter a maior presença em mercados de países emergentes com novos produtos. $\mathrm{O}$ conglomerado $\mathrm{V}$ apresenta a maior presença em mercados de países industrializados com novos produtos. Dadas essas características dos conglomerados e considerando as explicações sobre papéis estratégicos, justifica-se denominar o primeiro conglomerado adaptador local; o segundo, inovador nascente; o terceiro, inovador local; o quarto, inovador para países emergentes; e o quinto, inovador global.

Para validar a solução de conglomerados, foram usadas várias técnicas, tais como a análise multivariada de variância (Manova; teste Pillai's, Roy, Wilk's, Hotellings $\mathrm{T}^{2}$ são significativos no nível de 0,01 ), a análise de uma amostra parcial, o uso de um procedimento diferente e a validade preditiva com base em um referencial teórico existente. Em geral, as diferentes técnicas usadas para a validação demonstram que há diferentes grupos de UDPs, que se destingem significativamente em relação às variáveis escolhidas.

\section{Caracterização dos conglomerados}

De acordo com o foco deste artigo, os cinco conglomerados serão caracterizados usando-se dois construtos, a autonomia e a competição interna, assim como seus respectivos indicadores.

A Tabela 2 mostra os escores relativos ao grau de autonomia da UDP na área de desenvolvimento de produtos. A escala somada autonomia discrimina os cinco conglomerados de forma significativa $\left(\chi^{2}=13,27 ; p=0,01\right)$, portanto, a hipótese $\mathrm{H}_{1}$ é rejeitada. Os testes Mann-Whitney ajudam a identificar quais dos conglomerados são significativamente diferentes e quais não o são. A comparação dos coeficientes indica que os conglomerados III (inovador local) e V (inovador global) possuem uma alta autonomia ou baixo controle exercido pela matriz (escores 0,63 e 0,41) e se distinguem de forma significativa de outros conglomerados. No caso do conglomerado IV (inovador para mercados emergentes), a autonomia é tão baixa como no conglomerado I (adaptador local), mas a diferença frente a outros conglomerados não é significativa.

É importante notar que as diferenças entre os conglomerados III e II, I são significativas nos níveis de 0,05 e

Tabela 2 - A autonomia nos cinco conglomerados

\begin{tabular}{|c|c|c|c|c|c|c|c|c|}
\hline \multirow[b]{2}{*}{ VARIÁVEL / INDICADORES } & \multicolumn{5}{|c|}{ CONGLOMERADOS } & \multicolumn{2}{|c|}{ KRUSKAL WALLIS } & \multirow{2}{*}{$\begin{array}{c}\text { DIFERENÇAS } \\
\text { ENTRE } \\
\text { CONGLOMERADOS } \\
\text { (MANN-WHITNEY) }\end{array}$} \\
\hline & $\begin{array}{c}\text { I } \\
(n=74)\end{array}$ & $\begin{array}{c}\text { II } \\
(n=36)\end{array}$ & $\underset{(n=16)}{\text { III }}$ & $\underset{(n=9)}{\text { IV }}$ & $\underset{(n=11)}{\text { IV }}$ & $\mathrm{Chi}^{2}$ & p & \\
\hline $\begin{array}{l}\text { Autonomia (soma de coeficientes } \\
\text { de regressão, todos os itens) }\end{array}$ & $-0,20$ & 0,07 & 0,63 & $-0,21$ & 0,41 & 13,27 & 0,01 & $\begin{array}{l}\mathrm{III}>\mathrm{II}, \mathrm{III}>\mathrm{I}^{* *}, \\
\mathrm{II}>\mathrm{I}^{* *}, \mathrm{~V}>\mathrm{I}^{*}\end{array}$ \\
\hline Adaptação (14) & $-0,13$ & 0,10 & 0,39 & $-0,18$ & 0,11 & 3,78 & 0,44 & - \\
\hline Novo produto nacional (15) & $-0,12$ & 0,01 & 0,70 & $-0,33$ & 0,06 & 9,48 & 0,05 & III $>$ I** \\
\hline Novo produto exterior (16) & $-0,16$ & 0,05 & 0,51 & 0,10 & 0,09 & 8,57 & 0,07 & III $>$ I** \\
\hline Lançamento nacional (17) & $-0,10$ & 0,03 & 0,44 & $-0,22$ & 0,12 & 4,57 & 0,33 & III $>I^{*}$ \\
\hline Lançamento exterior (18) & $-0,10$ & 0,10 & 0,16 & $-0,32$ & 0,36 & 5,43 & 0,25 & - \\
\hline Orçamento (19) & $-0,12$ & 0,07 & 0,34 & $-0,39$ & 0,38 & 3,69 & 0,45 & - \\
\hline Cooperação (20) & $-0,23$ & 0,03 & 0,38 & 0,26 & 0,66 & 13,08 & 0,01 & V>II, I**; III > I* \\
\hline
\end{tabular}

Nota: os números em parênteses correspondem aos itens no questionário; os coeficientes foram padronizados;

$* *$ = significativo em 0,$01 ; *$ = significativo em 0,$05 ;+=$ significativo em 0,1 . 
0,01 , entretanto, não se podem observar diferenças significativas entre os dois conglomerados voltados para mercados externos (IV e V) e entre estes conglomerados e os demais.

Note-se que a diferença entre os conglomerados II e III é uma justificativa adicional para trabalhar com cinco (em vez de quatro) conglomerados. O que sustenta a alta autonomia dos inovadores locais (conglomerado III) é sua maior liberdade para o desenvolvimento e o lançamento de novos produtos, principalmente para o mercado nacional, mas também para o mercado externo.

Em relação aos sete indicadores que compõem a variável autonomia, vale notar que existem diferenças significativas entre os conglomerados quanto ao desenvolvimento de novos produtos para o mercado nacional (indicador $\left.\mathrm{n}^{\circ} 15 ; \chi^{2}=9,48 ; \mathrm{p}=0,05\right)$, ao desenvolvimento de novos produtos para o mercado externo (indicador $\mathrm{n}^{\circ} 16 ; \chi^{2}=$ $8,57 ; \mathrm{p}=0,07)$, e à cooperação com parceiros no Brasil (indicador $\mathrm{n}^{\circ} 20 ; \chi^{2}=13,08 ; \mathrm{p}=0,01$ ). Vale notar também que os padrões nos indicadores seguem o mesmo padrão que a variável composta por eles.

Não parece haver diferenças significativas entre os conglomerados em relação à tomada de decisões sobre adaptação de produtos (indicador 14), o lançamento de novos produtos no exterior (indicador $n^{\circ} 18$ ) e o orçamento para atividades de DP (indicador $\mathrm{n}^{\circ} 19$ ).

A Tabela 3 mostra os escores relativos ao grau de competição interna na área de desenvolvimento de produtos. Com base nos resultados de uma análise fatorial, foi construída uma escala (usando coeficientes de regressão) que representa o construto "competição interna". Essa escala é composta por cinco itens: a competição entre as UDPs (indicador $n^{\circ} 23$ ), alocação de projetos por meio de leilões entre as UDPs (indicador $n^{\circ} 24$ ), vendas internas de serviços tecnológicos para outras subsidiárias da multinacional (indicador $n^{\circ} 25$ ), alocação de projetos em função do custo (indicador $\mathrm{n}^{\circ} 27$ ) e em função da qualidade de DP (indicador $n^{\circ} 29$ ). A escala discrimina os cinco conglomerados de forma significativa $\left(\chi^{2}=19,56 ; \mathrm{p}=0,00\right)$; logo, a hipótese $\mathrm{H}^{2}$ também pode ser rejeitada.

Os conglomerados IV e V, que estão fortemente orientados para mercados externos, apresentam alta competição interna (escores de 0,85 e 1,07 respectivamente). Os conglomerados I, II e III, que agrupam UDPs primordialmente voltadas para o mercado brasileiro, possuem baixos escores na escala competição interna $(-0,08,-0,11$ e $-0,58$ res-

Tabela 3 - Competição interna nos cinco conglomerados

\begin{tabular}{|c|c|c|c|c|c|c|c|c|}
\hline \multirow[b]{2}{*}{ VARIÁVEL / INDICADORES } & \multicolumn{5}{|c|}{ CONGLOMERADOS } & \multicolumn{2}{|c|}{ KRUSKAL WALLIS } & \multirow{2}{*}{$\begin{array}{l}\text { DIFERENÇAS ENTRE } \\
\text { CONGLOMERADOS } \\
\text { (MANN-WHITNEY) }\end{array}$} \\
\hline & $\underset{(n=74)}{I}$ & $\begin{array}{c}\text { II } \\
(n=36)\end{array}$ & $\begin{array}{c}\text { III } \\
(n=16)\end{array}$ & $\underset{(n=9)}{\mathrm{IV}}$ & $\begin{array}{c}V \\
(n=11)\end{array}$ & $\mathrm{Chi}^{2}$ & $\mathbf{p}$ & \\
\hline $\begin{array}{l}\text { Competição interna (coefi- } \\
\text { cientes de regressão, itens } \\
23,24,25,27,29 \text { ) }\end{array}$ & $-0,08$ & $-0,11$ & $-0,58$ & 0,85 & 1,07 & 19,56 & 0,00 & $\begin{array}{l}\mathrm{V}>\mathrm{I}, \mathrm{II}, \mathrm{III} * * \\
\mathrm{IV}>\mathrm{I}, \mathrm{II}, \mathrm{III**}\end{array}$ \\
\hline Duplicação (21) & $-0,13$ & 0,09 & 0,09 & 0,18 & 0,31 & 2,63 & 0,62 & - \\
\hline Cooperação (22) & $-0,07$ & 0,26 & 0,06 & $-0,04$ & $-0,43$ & 15,78 & 0,00 & $\mathrm{~V}<\|^{*}$ \\
\hline Competição (23) & $-0,07$ & $-0,13$ & $-0,38$ & 0,64 & 0,94 & 5,32 & 0,26 & $\begin{array}{l}V>I, I I, I I I^{* *} \\
I V>I, I I, I I *\end{array}$ \\
\hline Leilão (24) & 0,00 & $-0,13$ & $-0,51$ & 0,22 & 0,95 & 22,66 & 0,00 & $\mathrm{~V}>\mathrm{I}, \mathrm{II}, \mathrm{III} * *$ \\
\hline Vendas internas (25) & $-0,23$ & 0,09 & $-0,30$ & 1,16 & 0,76 & 12,32 & 0,02 & $\begin{array}{l}\mathrm{V}>\mathrm{I}, \mathrm{III} * * ; \mathrm{V}>\mathrm{II}^{+} \\
\mathrm{IV}>\mathrm{I}, \mathrm{II}, \mathrm{II} \mathrm{I}^{* *} ; \mathrm{II}>\mathrm{III}\end{array}$ \\
\hline Equipamentos (26) & 0 & 0 & $-0,26$ & $-0,05$ & 0,48 & 3,72 & 0,45 & - \\
\hline Custo (27) & 0,03 & $-0,05$ & $-0,35$ & 0,05 & 0,43 & 5,92 & 0,20 & $\mathrm{~V}>\mathrm{III}^{+}, \mathrm{V}>\mathrm{II}^{*}$ \\
\hline Mercado (28) & $-0,11$ & 0,11 & 0,26 & $-0,06$ & 0,08 & 2,33 & 0,68 & - \\
\hline Qualidade (29) & 0,05 & $-0,18$ & $-0,26$ & $-0,04$ & 0,67 & 8,01 & 0,09 & $\begin{array}{l}\mathrm{V}>\mathrm{III}^{+}, \mathrm{V}>\mathrm{II}^{* *} \\
\mathrm{~V}>\mathrm{I}^{*}\end{array}$ \\
\hline
\end{tabular}

Nota: os números em parênteses correspondem aos itens no questionário; os coeficientes foram padronizados;

$* *$ = significativo em 0,$01 ; *$ = significativo em 0,$05 ;+=$ significativo em 0,1 . 
pectivamente). Como indicam os testes de Mann-Whitney, os dois conglomerados voltados para mercados externos, IV e V, se distinguem significativamente dos conglomerados primordialmente voltados para o mercado brasileiro (I, II e III). Observando cada um dos cinco indicadores $(23,24,25,27,29)$ que compõem a escala (variável) de competição interna, pode-se constatar que eles estão em conformidade com esse padrão.

Embora as diferenças não sejam sempre significativas, parece haver bastante coerência entre os resultados e o padrão previsto, o que indica uma certa relevância desses itens. Por exemplo, os itens duplicação (item 21) e cooperação (item 22) estão em conformidade com o padrão previsto, já que uma maior duplicação de equipamentos (várias UDPs da multinacional podem realizar o mesmo tipo de atividades) pode implicar uma maior concorrência ou menor cooperação e vice-versa.

Quanto aos quatro critérios para a atribuição de projetos a UDPs, os escores dos itens custo (item 27) e qualidade (item 29) são mais altos no conglomerado V (0,43 e 0,67 respectivamente) e mais baixos no conglomerado III (-0,35 e - $-0,26$ respectivamente), enquanto o tamanho do mercado apresenta o escore mais alto no conglomerado III $(0,26)$. Isso sugere que é o mercado local que parece influenciar as atividades de DP dos inovadores locais, enquanto a relação custo-qualidade tende a influenciar as atividades de DP dos inovadores globais.

\section{DISCUSSÃO DE RESULTADOS}

Os três conglomerados primordialmente voltados para inovação (desenvolvimento de novos produtos) nem sempre possuem alta autonomia na tomada de decisões e nem sempre são expostos à alta competição interna. Logo, ambas as variáveis não ajudam a discriminar as UDPs mais inovadoras das menos inovadoras.

No que diz respeito aos dois conglomerados voltados para mercados externos, um deles apresenta um alto nível de autonomia decisória, enquanto o outro mostra uma baixa autonomia. No entanto, é importante notar que as diferenças entre os dois conglomerados voltados para mercados externos, assim como entre cada um deles e os conglomerados voltados para o mercado doméstico, não são significativas. Em outras palavras, o conceito autonomia não parece ser muito útil para a distinção entre os papéis estratégicos de UDPs voltadas para o mercado local e os papéis daquelas voltadas para o mercado externo. Assim, a presente pesquisa contradiz os resultados de Birkinshaw, Hood e Jonsson (1998), que encontraram uma relação positiva entre o papel estratégico do contribuinte para projetos globais de $\mathrm{P} \& \mathrm{D}$ e a autonomia de decisão.

A competição interna, entretanto, distingue clara e significativamente os conglomerados com escopo no mercado local daqueles com escopo no mercado externo. Logo, o conceito competição interna parece ser mais indicado para a distinção entre papéis estratégicos globais e papéis locais do que o conceito autonomia.

Ora, esta pesquisa traz à tona que a existência de competição entre as UDPs pode favorecer as UDPs pesquisadas a se inserirem em mercados externos. Quais as possíveis explicações para tal resultado? É possível que as UDPs possuam vantagens em custo, estando elas localizadas em um país de médio custo com um nível razoável de capacitação de mão-de-obra em engenharia e ciências. Essa posição pode lhes conferir vantagens competitivas frente a outras UDPs da mesma multinacional que estão localizadas em países de alto custo como a Europa ocidental, Japão e Estados Unidos. Em conclusão, as UDPs, e, por extensão, as subsidiárias localizadas em países de médio ou baixo custo podem aumentar sua importância nas atividades inovadoras das suas multinacionais desde que essas multinacionais usem a competição interna como forma de coordenação.

Os três conglomerados primordialmente voltados para o mercado local apresentam diferenças notáveis em relação à variável autonomia. Pode-se observar que o grau de autonomia aumenta do adaptador local (menor nível de autonomia) para o inovador nascente (nível de autonomia médio) e deste para o inovador local (maior nível de autonomia). Assim, a variável autonomia de decisão distingue significativamente esses três conglomerados voltados para o mesmo mercado.

Como se pode explicar tal fenômeno? Provavelmente, a maior autonomia de decisão explica uma maior capacidade inovadora de UDPs voltadas para o mercado local. Nesse sentido, os resultados referentes ao conceito de autonomia estão em conformidade com os resultados de Ghoshal and Bartlett (1988), que encontraram uma correlação positiva e altamente significativa entre autonomia local e criação de inovações.

Com base nisso, podemos conjeturar que o conceito autonomia pode servir para discriminar papéis estratégicos mais inovadores de menos inovadores desde que possuam o mesmo escopo geográfico em termos de mercados atendidos. Futuras pesquisas podem testar ainda se essa proposição também é válida para os outros dois tipos de mercados: mercados de países emergentes e de países industrializados. 


\section{CONCLUSÕES}

Este estudo proporcionou várias contribuições referentes às atividades de desenvolvimento de produto (DP) em subsidiárias de empresas multinacionais localizadas no Brasil. Primeiramente, foram classificadas as unidades de desenvolvimento de produto dessas subsidiárias em cinco grupos significativamente distintos. (I) Os adaptadores locais adaptam produtos desenvolvidos no exterior para o mercado brasileiro, possuem baixa autonomia e estão expostos a um grau médio de competição interna. (II) Os inovadores nascentes são caracterizados por um grau médio de autonomia e competição interna; eles adaptam e melhoram produtos desenvolvidos no exterior, mas também dedicam uma parte considerável, porém ainda minoritária, das suas atividades ao desenvolvimento de novos produtos próprios, principalmente para o mercado local. (III) Os inovadores locais dedicam a maior parte das suas atividades ao desenvolvimento de novos produtos para o mercado local e convivem com alta autonomia e baixa competição interna. (IV) Os inovadores para mercados emergentes concentram uma parte considerável, porém ainda minoritária, das suas atividades no desenvolvimento de novos produtos para mercados emergentes; a competição entre eles e outras unidades da multinacional é alta e a sua autonomia é baixa. (V) Os inovadores globais, caracterizados por alta autonomia e alta exposição à competição interna, destinam a maior parte das suas atividades ao desenvolvimento de novos produtos principalmente para países industrializados.

Essa classificação mostrou que cerca da metade da amostra está constituída por adaptadores locais e apenas cerca de um quarto da amostra pode ser considerada como inovadora em termos de criações de novos produtos. Nesse sentido, os resultados desta pesquisa são distintos daqueles que foram realizados em países industrializados, onde os grupos estratégicos de subsidiárias com escopo internacional e atividades inovadoras possuem um tamanho maior (Gupta e Govindarajan, 1994; Nobel e Birkinshaw, 1998). Embora os dados dessas pesquisas não possam ser comparados diretamente, o menor número de unidades voltadas para atividades inovadoras e para o mercado internacional confirma a concepção de que o Brasil é predominantemente um receptor de tecnologia (Katz, 2000). No entanto, há indícios de que cerca de $80 \%$ das unidades brasileiras desenvolvem novos produtos, embora isso não seja a sua atividade principal.

Quanto ao escopo geográfico das suas atividades, apenas dois grupos pequenos (IV e V), que acumulam 13\% da amostra, são predominantemente voltados para o mer- cado internacional. Todavia, outros dados da pesquisa indicam que mais de $40 \%$ da amostra total desenvolve algum novo produto para mercados externos, embora essa não seja a atividade principal dessas unidades. Essa composição da amostra indica que a maioria das subsidiárias brasileiras tem ainda um considerável caminho de evolução para elevar seu papel na estratégia de inovação das multinacionais.

Vale destacar um papel estratégico específico, o inovador para os países emergentes, pois este ainda não foi considerado em outras pesquisas e parece ser especialmente relevante para uma economia emergente como o Brasil. Algumas unidades que adaptam, melhoram ou desenvolvem novos produtos para mercados emergentes provavelmente podem ser caracterizadas como centros ou matrizes regionais. A posição do Brasil como o país latino-americano mais industrializado pode ser uma das razões pela quais algumas das multinacionais atribuem a unidades brasileiras essa responsabilidade.

Em segundo lugar, a presente pesquisa mostrou que é possível explicar esses papéis estratégicos com base em dois conceitos, a autonomia de decisão da subsidiária e a competição interna entre as unidades da multinacional. Os dois conceitos tratam de diferentes modos de coordenação das atividades das multinacionais. A autonomia representa o grau de hierarquia presente nas relações entre a matriz e as subsidiárias, enquanto a competição interna representa a existência ou não de incentivos econômicos, que podem reger as relações entre as unidades da multinacional e elevar a eficiência da organização multinacional como um todo.

Mais especificamente, argumentou-se que uma alta exposição à competição interna pode incentivar unidades que apresentam vantagens relativas em custos e qualidade a inovar para mercados externos. Contudo, mostrouse que o conceito da autonomia decisória pode explicar uma maior capacidade inovadora em unidades voltadas para o mercado local.

A partir desses resultados, é possível concluir que uma subsidiária requer um maior grau de autonomia decisória para o desenvolvimento de capacidades inovadoras e prontidão ao mercado local. A integração na estratégia global de pesquisa e desenvolvimento de produtos da multinacional, no entanto, pode levar à perda da autonomia decisória da subsidiária. Os resultados sugerem também que as multinacionais que incentivam a competição entre suas subsidiárias tendem a deslocar as atividades de desenvolvimento de produtos para países de baixo e médio custo desde que eles possuam um nível satisfatório de capacidades tecnológicas. 
Esta pesquisa também oferece uma contribuição metodológica, visto que o conceito de competição interna foi primeiramente operacionalizado para uma amostra maior. Dessa forma, evolui-se em relação aos estudos nos quais se baseia este trabalho.

A principal limitação da pesquisa consiste no uso de apenas dois conceitos para explicar os papéis estratégicos. Futuras pesquisas poderiam considerar outras variáveis, tais como as relações externas com clientes ou fornecedores da subsidiária. Por fim, a classificação de empresas é limitada, porque não permite enxergar a evolução dos papéis. Futuras pesquisas poderiam esclarecer como as subsidiárias atingem determinados papéis nas estratégias de inovação das multinacionais.

\section{REFERÊNCIAS}

ANDERSSON, U.; FORSGREN, M. In Search of centre of excellence: network embeddedness and subsidiary roles in multinational companies. Management International Review, v. 40, n. 4, p. 329-350, 2000.

ASAKAWA, K. Evolving headquarters-subsidiary dynamics in international R\&D: the case of Japanese multinationals. R\&D Management, v. 31, n. 1, p. 1-14, 2001.

BARTLETT, C.; GHOSHAL, S. Managing Across Borders: The Transnational Solution. Boston: Harvard Business School Press, 1989.

BIRKINSHAW, J.; HOOD, N. Multinational subsidiary evolution: capability and charter change in foreign-owned subsidiary companies. The Academy of Management Review, v. 23, n. 4, p. 773-796, 1998.

BIRKINSHAW, J.; HOOD, N.; JONSSON, S. Building firm-specific advantages in multinational corporations: the role of subsidiary initiative. Strategic Management Journal, v. 19, n. 3, p. 221-241, 1998.

BIRKINSHAW, J.; FEY, C. Building an internal market system: insights from five R\&D organizations. In: BIRKINSHAW, J.; HAGSTROM, P. (Eds.). The Flexible Firm: Capability Management in Network Organizations. Oxford: Oxford University Press, p. 149-175, 2000.

BIRKINSHAW, J.; MORRISON, A. Configurations of strategy and structure in subsidiaries of multinational corporations. Journal of International Business Studies, v. 26, n. 4, p. 729-754, 1995.

BOEHE, D. M.; ZAWISLAK, P. R\&D roles in subsidiaries of multinational companies: when does the institutional environment matter? In: DRUID SUMMER CONFERENCE 2004, Denmark. Disponível em <http://www. druid.dk/ocs/viewabstract.php?id=66\&cf=l>. Acessado em abr. 2005.
CAMARGOS, S. P. Inserção das afiliadas brasileiras na estrutura de P\&D das empresas internacionais. In: SIMPÓSIO DA INOVAÇÃO TECNOLÓGICA, 4., 2000, São Paulo. Anais. São Paulo, 2000.

CONSONI, F. L. Da tropicalização ao projeto de veículos: um estudo das competências em desenvolvimento de produção de produtos nas montadoras de automóveis no Brasil. 2004. Tese (Doutorado em Política Científica e Tecnológica), Unicamp, Campinas, 2004.

COSTA, I.; QUEIROZ, S. Foreign direct investment and technological capabilities in Brazilian industry. Research Policy, v. 31, n. 8/9, p. 143143, 2002

CYERT, R.; MARCH, J. A Behavioral Theory of the Firm. Englewood Cliffs: Prentice-Hall, 1963.

DOGHERTY, S.; INKLAAR, R.; MCGUCKIN, R.; VAN ARK, B. Performing research and development abroad - international comparisons of costs and value, interim report on NSF project on internationally comparable science, technology and competitiveness indicators, August 2002. Disponível em <http://www.eco.rug.nl/medewerk/inklaar/papers/R\&DInterim.pdf>. Acessado em fev. 2005

FEINBERG, S. Do world product mandates really matter? Journal of International Business Studies, v. 31, n. 1, p. 155-167, 2000.

FIGUEIREDO, P. Aprendizagem tecnológica e performance competitiva. Rio de Janeiro, FGV Editora, 2003.

FROST, T.; BIRKINSHAW, J.; ENSIGN, P. Centers of excellence in multinational corporations. Strategic Management Journal, v. 23, n. 11, p. 997-1018, 2002

GALINA, S. Desenvolvimento global de produtos: O papel das subsidiárias brasileiras de fornecedores de equipamentos do setor de telecomunicações. 2003. Tese (Doutorado em Engenharia de Produção), Escola Politécnica da USP, São Paulo, 2003

GHOSHAL, S.; BARTLETT, C. Creation, adoption and diffusion of innovations by subsidiaries of multinational companies. Journal of International Business Studies, v. 19, p. 365-388, 1988.

GHOSHAL, S.; BARTLETT, C. The multinational corporation as a network: perspectives from interorganizational theory. Academy of Management Review, v. 15, n. 4, p. 603-625, 1990.

GUPTA, A.; GOVINDARAJAN, V. Knowledge flows and the structure of control within multinational corporations. Academy of Management Review, v. 16, n. 4, p. 768-792, 1991.

GUPTA, A.; GOVINDARAJAN, V. Organizing for Knowledge Flows within MNCs, International Business Review, v. 3, n. 4, p. 443-457, 1994.

HENNART, J.-F. The Swollen Middle: a mix of market and hierarchy. Organization Science, v. 4, n. 4, p. 529-547, 1993. 
HOLM, U.; PEDERSEN, T. The Emergence and Impact of MNC Centres of Excellence: a Subsidiary Perspective. London, McMillan Press, 2000.

KATZ, J. Pasado y presente del comportamiento tecnológico de América Latina. Santiago, Cepal, Serie Desarrollo Productivo, n. 75, 2000.

LALL, S. Technological capabilities and industrialization. Word Development, v. 20, n. 2, p. 165-186, 1992.

NOBEL, R.; BIRKINSHAW, J. Innovation in multinational corporations: control and communication patterns in international R\&D operations. Strategic Management Journal, v. 19, n. 5, p. 479-496, 1998.

O'DONNELL, S. Managing Foreign subsidiaries: agents of headquarters, or an interdependent network? Strategic Management Journal, v. 21, n. 5, p. $525-548,2000$

OLIVEIRA JUNIOR, M.; BORINI, F. Proposição de uma tipologia das subsidiárias estrangeiras no Brasil: resultados de evidências empíricas. In: ENCONTRO NACIONAL DA ASSOCIAÇÃO NACIONAL DOS PROGRAMAS DE PÓS-GRADUAÇÃO E PESQUISA EM ADMINISTRAÇÃO, Brasília. Anais. Brasília: Anpad, 2005.

PATERSON, S.; BROCK, D. The development of subsidiary management research: review and theoretical analysis. International Business Review, v. 11, p. 139-163, 2002.
ROTH, K.; MORRISON, A. An empirical analysis of the integration-responsiveness framework in global industries. Journal of International Business Studies, v. 21 n. 4, p. 541-565, 1990.

RUGMAN, A.; VERBEKE, A. Subsidiary specific advantages in multinational enterprises. Strategic Management Journal, v. 22, n. 3, 237-250, 2001.

SCHÜTTE, H. Between headquarters and subsidiaries: the RHQ solution In: BIRKINSHAW, J.; HOOD, N. (Eds.). Multinatinoal Corporate Evolution and Subsidiary Development. Basingstroke: McMillan, 1998. p. 189-212.

TAGGART, J. Autonomy and procedural justice: a framework for evaluating subsidiary strategy. Journal of International Business Studies, v. 28, n. 1, p. 51-76, 1997.

UNITED NATIONS. World Investment Report 2005: Transnational Corporations and the Internationalization of R\&D. United Nations, New York \& Geneva, 2005.

WEBER, M. Ensaios de sociologia. Rio de Janeiro: Zahar, 1963.

YOUNG, S.; TAVARES, A. Centralization and autonomy: back to the future. International Business Review, v. 13, n. 2, p.215-237, 2004.

Artigo recebido em 09.10.2005. Aprovado em 14.07.2006.

\author{
Dirk Michael Boehe \\ Professor Adjunto no curso de Mestrado em Administração da Universidade de Fortaleza. \\ Doutor em Administração pela UFRGS. \\ Interesses de pesquisas nas áreas de gestão da tecnologia e da inovação, estratégias de in- \\ ternacionalização de empresas, offshoring de serviços de TI, empresas multinacionais em \\ mercados emergentes. \\ E-mail:dmboehe@unifor.br \\ Endereço: Rua Silva Jatahay, 90/402, Meireles, Fortaleza - CE, 60165-070.
}

